Bulletin de la Société Royale des Sciences de Liège, Vol. 85, 2016, p. 890 - 911

\title{
Facile Preparation of Mesoporous $\gamma$-Alumina Nanoparticles with High- Surface-Area via Sol-Gel Method and their Efficiency for the Removal of Lead from Aqueous Solution
}

\author{
Seyed Mahdi Siahpoosh, Esmaeil SALAHI*, Fereidoun Alikhani HeSSARI, \\ Iman MOBASHERPOUR
}

Materials and Energy Research Center (MERC), P.O. Box 14155-477, Tehran, Iran

\begin{abstract}
In the present investigation, $\gamma$-alumina nanoparticles with high specific surface area (351 $\mathrm{m}^{2} / \mathrm{g}$ ) and relatively narrow pore size distribution was prepared using sol-gel method in the presence of aluminum isopropoxide as an aluminum precursor, distilled water, acetic acid as hydrolysis rate controller and tert-butanol as solvent.

The calcined $\gamma$-alumina nanoparticles were characterized using X-ray diffractometer (XRD), scanning electron microscope (SEM) and nitrogen adsorption-desorption techniques.

Prepared $\gamma$-alumina was tested for the adsorption of $\mathrm{Pb}^{2+}$ from aqueous solution at toxic metal concentrations, and isotherms were determined. The $\mathrm{Pb}^{2+}$ adsorption performance of the as-prepared samples was studied by atomic adsorption spectroscopy (AAS) method.

According to the results, the prepared $\gamma$-alumina showed the great adsorption performance of $\mathrm{Pb}^{2+}$ with a high adsorption rate and adsorption capacity of $1150 \mathrm{mg} / \mathrm{g}$ when the adsorption reached to equilibrium for $5 \mathrm{~min}$ at room temperature and $\mathrm{pH}=5.5$. The adsorbed amount increased rapidly with $\mathrm{pH}$ variation from $\mathrm{pH} 3$ to 9 . The optimum contact time, initial concentration of adsorbate, adsorbent mass and $\mathrm{pH}$ were determined and Langmuir, Freundlich and Tempkin adsorption models were obtained using metal ions concentrations in ranging from 100 to $400 \mathrm{mg} / \mathrm{L}$. Correlation coefficients $\left(\mathrm{R}^{2}\right)$ of Langmuir, Freundlich and Tempkin adsorption isotherms were 0.9994, 0.9975 and 0.9982, respectively, and Langmuir isotherm was more suitable for adsorption on $\gamma$-alumina than others. Also presence of $\mathrm{Pb}^{2+}$ ions has been confirmed by infrared spectroscopy.

Efficient synthesis strategy, exceptionally high specific surface area and high adsorption efficiency of these mesoporous $\gamma$-alumina nanoparticles showed an excellent ability to remove $\mathrm{Pb}^{2+}$ heavy metal ions from aqueous solution that could find potential utility in the purification of polluted water.
\end{abstract}

Keywords: $\gamma$-Alumina, Nanoparticles, Sol-gel, Adsorption, Lead, Isotherm.

\footnotetext{
* Corresponding author. Tel.: +98 $2616204131 / 912$ 1500168; Fax: +98 2616201888.
}

E-mail address: e-salahi@merc.ac.ir 
Bulletin de la Société Royale des Sciences de Liège, Vol. 85, 2016, p. 890 - 911

\section{INTRODUCTION}

Adsorption performance of different alumina compounds, especially $\alpha$-alumina, was investigated in many researches and various results have been reported, but properties of $\gamma$ alumina have been studying less than the others. A variety of conditions are affecting on adsorb behavior such as method of preparation, morphology and crystallinity of the used adsorbent, the type of adsorbent and etc. [1]. it could be noted that of the needs of a suitable solid adsorbent high specific surface area of its particles, controlled dimensions of particles, high capacity of heavy metals adsorption, high speed adsorbent restoration and low manufacturing cost also various factors such as type and concentration of adsorbates, type and concentration of adsorbent, time and temperature while stirring adsorption, $\mathrm{pH}$ of solution affected on the adsorption rate.

Nowadays the preparation of nanostructures has gained significant importance with phase characteristics, size and shape of the particles and the controllable crystallinity, using methods such as hydrolysis, thermal decomposition, chemical vapor deposition, sol-gel, etc. [2 and 3]. Wang et al. [4] prepared alumina nano fibers by hydrolyzing aluminum nitrate in the presence of hexamethylenetetramine. Rajendran and Bhattacharya [5] used the sol-gel emulsion method to obtain thermally stable alumina spheres with diameter less than $1 \mathrm{~mm}$.

Vallet-Regí et al. [6] used the spray pyrolysis method and Károly and Szépvölgyi [7] used thermal plasma to obtain hollow alumina spheres with diameter less than $100 \mu \mathrm{m}$.

Single crystalline nanorods were prepared by Y.J.Zhu et al. [8] using thermal decomposition of boehmite precursor. Also in the other research, H.Y.Zhu et al. [9] synthesized $\gamma$-alumina nano fibers from aluminum hydrate colloids using polyethylene oxide surfactant. Shen et al. [10] developed a simple solid-phase method for the synthesis of high quality boehmite and $\gamma$-alumina nanorods. Palkar [11] obtained porous spheres of $\gamma$-alumina with $0.5 \mathrm{~mm}$ diameter using the solgel process. Also Santos et al. [1] provided macro pores $\gamma$-alumina based on gel process with or without presence of porosity maker particles such as soot and sawdust.

Ji et al. [12] produced meso porosity alumina, with high specific surface area using the precursor of tri-sec-butoxide aluminum. By the similar raw material, Valente et al. [13] produced $\gamma$-alumina and Ki-Won Jun et al. [14] prepared the $\gamma$-alumina activated by silica and Woodfield et al. [15] synthesized the meso pore $\gamma$-alumina. Rezaei et al. [16] produced nanocrystalline $\gamma$ alumina with sucrose surfactants and showed increasing of the specific surface area and particle size reduction of resulted $\gamma$-alumina. However, Liu et al. [17] did not use surfactants due to the thermal instability, environmental risks and the high price in the preparation of $\gamma$-alumina.

Peng et al. [18] produced $\gamma$-alumina with a specific surface area of $158 \mathrm{~m}^{2} / \mathrm{g}$ with a chemical deposition process at room temperature in an aqueous solution using ammonium bicarbonate and various aluminum mineral salts. Jun et al. [19] and Zhai et al. [20] also synthesized $\gamma$-alumina particles in the same way and using low-cost aluminum nitrate and aluminum chloride, respectively, but the relatively high and useful specific surface area for the adsorption process was not found.

Various properties of alumina adsorption were studied much less in comparison with other adsorbent materials, yet. Mahmoud et al. [21] using a commercial alumina with specific surface area of about $155 \mathrm{~m}^{2} / \mathrm{g}$, to investigation of heavy metal adsorption process and found to maximize the adsorption capacity $29 \mathrm{mg} / \mathrm{g}$. Providing $\gamma$-alumina from sodium aluminate derived from scrap aluminum, as a cheap precursor by precipitation with sulfuric acid is performed by Asencios et al. [22]. After calcination in $773 \mathrm{k} \gamma$-alumina was obtained, and it was used for the 
Bulletin de la Société Royale des Sciences de Liège, Vol. 85, 2016, p. 890 - 911

adsorption of cadmium, zinc and lead heavy metals from aqueous solutions. Bhaumik et al. [23] have prepared meso pore $\gamma$-alumina with specific surface area of about $250 \mathrm{~m}^{2} / \mathrm{g}$ and $2-10 \mathrm{~nm}$ particle diameter using sodium salicylate and have studied its ability to adsorb arsenic by it. Mousavi Zavvar et al. [24] also used $\gamma$-alumina obtained by solvent burning for the Zn heavy metal adsorption and reached to maximum adsorption capacity $58 \mathrm{mg} / \mathrm{g}$. Yu et al. [25] investigated the impact of environmental conditions on the adsorption behavior of ${ }^{63} \mathrm{Ni}$ (II) on the surface of commercial $\gamma$-alumina, in their study.

In the present study, it is focused on $\gamma$-alumina nanoparticles preparation based on sol-gel method at low temperature with specific surface area higher than $350 \mathrm{~m}^{2} / \mathrm{g}$, high pore volume and well defined narrow pore size distribution for $\mathrm{Pb}^{2+}$ adsorption. This research was also emphasized on using almost cheap raw materials with accepted level of purity.

\section{EXPERIMENTAL PROCEDURE}

\subsection{Starting Materials}

Preparation of the good quality $\gamma$-alumina nanoparticles was done by sol-gel method from almost cheaper raw materials without environmental pollution which has a high purity. Aluminum isopropoxide alkoxide as aluminum precursor instead of aluminum inorganic salt will produce $\gamma$-alumina powder with a higher specific surface area. On the other hand, this material is cheaper and easily available rather than many other alkoxides such as tri-sec-butoxide aluminum. Aluminum isopropoxide (AIP, $\mathrm{Al}\left(\mathrm{OCH}\left(\mathrm{CH}_{3}\right) \mathrm{CH}_{3}\right)_{3},>98.0 \%$ wt\%, MERCK Art. No.801079), tert-butanol $\left(\left(\mathrm{CH}_{3}\right)_{3} \mathrm{COH},>99.0 \%\right.$ wt\%, MERCK Art. No.822264), and acetic acid (AA, $\mathrm{CH}_{3} \mathrm{CO}(\mathrm{OH}),>63.0 \%$ wt $\%$, MERCK Art. No.62) were used as starting materials. In all preparations distilled water was used.

All solutions for the $\mathrm{Pb}$ heavy metal sorption experiments were prepared using Lead nitrate salt $\left(\mathrm{Pb}\left(\mathrm{NO}_{3}\right)_{2}, \geq 99.5 \% \mathrm{wt} \%\right.$, MERCK Art. No.107398). The aqueous solution initial $\mathrm{pH}$ was adjusted to the desired value using negligible amount of 0.01 or $0.1 \mathrm{M}$ nitric acid $\left(\mathrm{HNO}_{3}, \geq 65.0 \% \mathrm{wt} \%\right.$, MERCK Art. No.100443) or ammonia $\left(\mathrm{NH}_{3}, \geq 25.0 \% \mathrm{wt} \%\right.$, MERCK Art. No. 105432) solution.

All Materials were of analytical grade reagents and used as received without further purification. All glassware was cleaned with nitric acid, rinsed thoroughly and dried before use.

\subsection{Synthesis of $\gamma$-Alumina}

All experiments were conducted under air atmosphere. Aluminum isopropoxide was used as an aluminum precursor, acetic acid as hydrolysis rate controller and tert-butanol as solvent during synthesis. The weight ratios of reactants AIP: Solvent, AIP: $\mathrm{H}_{2} \mathrm{O}$, and AIP: AA were 1:60, 1:1, and 40:1 during processing, respectively. Initially, $3 \mathrm{~g}$ ( $15 \mathrm{mmol})$ of AIP was added to tert-butanol solvent to 0.065 molar AIP solution was prepared, under continuous and vigorous magnetic stirring at room temperature for $3 \mathrm{~h}$ until all AIP particles dissolved. Then, the mixture of $0.07 \mathrm{ml}(1 \mathrm{mmol})$ acetic acid and $3 \mathrm{ml}(166 \mathrm{mmol})$ distilled water was added drop-wise into the above solution. The solution was magnetically stirred for $3 \mathrm{~h}$ for completion of hydrolysis.

In all time the reaction, solution was stirred at $150 \mathrm{rpm}$ to form a uniform product. On completion of addition of two solutions together, the final solution was placed in a glass vessel at room temperature for $24 \mathrm{~h}$ resulted in formation of the gel material. Finally, the gel was dried in an oven at $120^{\circ} \mathrm{C}$ for $6 \mathrm{~h}$ in flow of air. Obtained white dry gel, was pulverized and passed through a 70 mesh sieve to the next test to be done on it.

Heat treatment for powder calcination was took place in a normal environment, using a laboratory chamber furnace which equipped with thermal string of silicon carbide and the ability to reach $1500^{\circ} \mathrm{C}$ maximum temperature. The sample was poured in an alumina crucible and was heated to $600^{\circ} \mathrm{C}$ with ramp rate of $2^{\circ} \mathrm{C} / \mathrm{min}$ and was maintained in that temperature for 6 hours so that obtained $\gamma$-alumina white powder after slow and gradual cooling in the furnace. A ramp rate of $2^{\circ} \mathrm{C} / \mathrm{min}$ was used to (1) avoid rapid 
Bulletin de la Société Royale des Sciences de Liège, Vol. 85, 2016, p. 890 - 911

dehydration to ensure uniform pore construction and (2) ensure uniform heat transfer to achieve better homogeneity and avoid rapid grain growth [15].

Reactivity of precursors depends on the chemical properties of them [26]. Aluminum isopropoxide is sensitive to moisture and even air moisture is sufficient for the start of hydrolysis reaction. The performed final reaction at low temperature is shown in follow:

$$
\mathrm{Al}(\mathrm{OR})_{3}+2 \mathrm{H}_{2} \mathrm{O} \rightarrow \mathrm{AlO}(\mathrm{OH})+3 \mathrm{R}(\mathrm{OH})
$$

In this reaction, $\mathrm{R}$ is the propyl group $\left(-\mathrm{C}_{3} \mathrm{H}_{7}\right)$. Accordingly, the hydrolysis reaction is done completely, due to high water content and high tendency of the aluminum isopropoxide to reaction with water. Using of aluminum isopropoxide precursor in solution, propylene glycol is formed as a by-product of the reaction as expected, in this research. But this compound is decomposed and came out of the system during calcination of prepared powder; without undesirable effects on the final product.

\subsection{Adsorption essay}

Uptake solutions in initial concentrations of $100,200,300$ and $400 \mathrm{mg} / \mathrm{L}$ of bivalent $\mathrm{Pb}^{2+}$ adsorbate in distilled water were prepared from the $\mathrm{Pb}\left(\mathrm{NO}_{3}\right)_{2}$ salt precursor.

The samples were taken as control sample from these solutions, before beginning the study of adsorption. $500 \mathrm{ml}$ of solution were mixed with a certain amount of prepared $\gamma$-alumina nanoparticles powder in certain conditions, to investigate the process of adsorption. Mixing operation was taking place in a clean glass jar on a magnetic stirrer (Heidolph MR $3001 \mathrm{~K}$ ).

The adsorption isotherms were obtained under favorable conditions for the adsorption of Lead, in contact time (adsorbate/adsorbent) of 3, 5, 10, 20, 30, 60 and 120 minutes, magnetic stirring at $300 \mathrm{rpm}$, adsorbent mass in solution $=0.02,0.04$ and $0.06 \mathrm{~g} / \mathrm{L}$, initial $\mathrm{pH}$ of Lead solution $=3$ to 9 and all solutions at room temperature (approximately $293 \mathrm{~K}$ ).

Heavy metal concentration in final solution was measured using atomic absorption spectrometry and the heavy metal adsorption and adsorption capacity per unit mass of adsorbent were calculated by comparing that with the initial concentration. After adsorption process, solid and liquid phases (adsorbate/adsorbent) were separated by centrifuging at $5000 \mathrm{rpm}$ for $30 \mathrm{~min}$ then filtration by Whatman filter paper and dried at room temperature, finally. The resulting precipitate was pulverized and passed through 70 mesh sieve until the experiments to be performed on them.

\subsection{Characterization}

\subsubsection{X-Ray Diffraction (XRD)}

Phase identification and crystallinity of the sample was done by X-ray diffraction using Siemens D-500, semi-automatic, at room temperature with $\mathrm{Cu}-\mathrm{K}_{\alpha}$ radiation. The sample diffraction intensity is measured in the Bragg angle $(2 \theta)$ range between $20-80^{\circ}$, a second residence time per step and 0.02 degrees of step size for each point. The data are collected with sample rotation. It is noteworthy that $\mathrm{Cu}-\mathrm{K}_{\alpha}$ radiation was obtained from a copper X-ray tube operated at $30 \mathrm{kV}$ and $25 \mathrm{~mA}(\lambda=1.5404 \AA)$. Obtained phase were identified by comparing the diffraction angle of XRD peaks with the corresponding intensity values in the ASTM cards and PANalytical X'pert High Score Plus software, 2.2b version by 2006-11-01 release date. The full width at half maximum (FWHM) is determined accurately after correcting for instrument broadening and the particle size is then estimated by using Scherer equation in nanometer [27]:

$$
D_{\mathrm{XRD}}=\frac{0.94 \lambda}{\beta \cos \theta}
$$


$\lambda$ is the wavelength of the incident radiation, $\beta$ is the full width of diffraction peak at half maximum intensity (FWHM) and $\theta$ is the diffraction angle. This equation can be used when the crystalline particle size is less than $1000 \AA$. Calculated particle size using this method is estimated and applying the correct ratio can be improved the accuracy of this method. In order to determine the particle size, the peaks of the pages with the maximum intensity were used, due to they have the clear and appropriate separation than the other peaks. Distance values between the crystal plates have been calculated by the equation (2), known as Bragg's law.

$$
\mathrm{n} \lambda=2 \mathrm{~d} \sin \Theta
$$

\subsubsection{Nitrogen Gas Adsorption/Desorption}

The specific surface area, the total pore volume, the average and distribution of pore diameter of the calcined sample was measured using a nitrogen gas adsorption/desorption isotherm from the curve data at liquid nitrogen temperature $(77.4 \mathrm{~K})$, using a Belsorp instrument (mini-II version). The pore volumes were determined at a relative pressure $\mathrm{P} / \mathrm{P}_{0}=0.99$. Specific surface areas were calculated using the Brunauer-Emmett-Teller (BET) equation, at $\mathrm{P} / \mathrm{P}_{0}$ range between 0.05-0.35. It should be noted that $\mathrm{P}$ is partial pressure in the adsorbed gas in equilibrium at $77.4 \mathrm{~K}$ by Pascal, and $\mathrm{P}_{\mathrm{o}}$ is the partial pressure in the adsorbed gas in experimental conditions by Pascal. Pore size distribution of the sample obtained employing the Barrett-Joyner-Hatenda $(\mathrm{BJH})$ model $\left(\mathrm{N}_{2}\right.$ gas adsorption on silica as reference). The as-prepared sample was degassed at $150^{\circ} \mathrm{C}$ in a vacuum flow for $12 \mathrm{~h}$ to remove the water and any impurities physisorbed on the solid surface. In this study, adsorption is usually expressed by the isotherms which are equivalent to the amount of adsorbed material on the surface of the adsorbent [28]. The contrary, desorption isotherms are obtained by measuring the amount of desorbed gas. Isotherms of I, II and III type is usually reversible, but I type could have a hysteresis loop. The hysteresis loop also can be seen in the type of IV and V. The hysteresis loop indicates on the presence of meso pores in the material and helps to achieve some information about the geometry of the pores. Assuming sphericity and same size of the particles, the measured specific surface area for the sample in crystallite forms was converted to equivalent particle size according to the equation (3) [29]:

$$
\mathrm{D}_{\mathrm{BET}}=\frac{6000}{\mathrm{p}^{5} \mathrm{EET}}
$$

$D_{\text {BET }}$ is the average particle size by $\mathrm{nm}, \mathrm{S}_{\mathrm{BET}}$ is the specific surface area expressed in $\mathrm{m}^{2} / \mathrm{g}$ and $\rho$ is the theoretical density expressed in $\mathrm{g} / \mathrm{cm}^{3}$.

\subsubsection{Scanning Electron Microscopy (SEM)}

The SEM images were obtained with a CAMBRIDGE-S360 scanning microscope operated at an acceleration voltage of $20 \mathrm{kV}$ and were used to study the surface of the adsorbent. To prototyping, powder samples were suspended in acetone to form a dilute suspension. One to two drops of the suspension, that its container was in the ultrasonic device, were dropped on clean glassy plates. After drying, the plates were used to produce microscopic images.

\subsubsection{Fourier Transform Infrared Spectroscopy (FTIRs)}

Infrared spectroscopy is an important tool in the identification of the functional groups that may be present in different substances. FTIR spectra of samples dispersed on $\mathrm{KBr}$ disks were recorded at room temperature using Perkin Elmer spectrometer (Spectrum 400, United States) over the range of 4000 to $400 \mathrm{~cm}^{-1}$ at a resolution of $4 \mathrm{~cm}^{-1}$ and 30 scans for each run. Disks were dried at $373 \mathrm{~K}$ for $24 \mathrm{~h}$ prior to recording the FTIR spectrum. 


\subsubsection{Atomic Absorption Spectroscopy (AAS)}

The initial and final concentrations of used heavy metal in the adsorption experiments were determined using atomic absorption spectroscopy (GBC932 Plus) that provided with hollow cathode lamp for Lead $(\lambda=217.0 \mathrm{~nm})$. Ensuring the results analysis, the test is repeated triplicate for each sample and the average of them was reported as the concentration of the solution.

In the study of adsorption process two fundamental and affecting factors are introduced [30]. The first factor is the amount of adsorbed heavy metal onto the adsorbent material per unit mass of adsorbent which is defined by the follow equation:

$$
\mathrm{q}_{\mathrm{t}}=\frac{\left(\mathrm{c}_{\mathrm{i}}-\mathrm{c}_{\mathrm{f}}\right) \times \mathrm{v}}{\mathrm{m}}
$$

where $C_{i}$ and $C_{f}$ are the initial and final concentration of the adsorbent in solution $(\mathrm{mg} / \mathrm{L})$ respectively, $\mathrm{V}$ is the solution volume containing heavy metal ions $\left(\mathrm{Pb}^{2+}\right)$ in liters, $\mathrm{m}$ is the adsorbent mass ( $\gamma$-alumina) in grams and $\mathrm{q}_{\mathrm{t}}$ is the adsorption capacity ( $\mathrm{mg}$ of adsorbate/g of adsorbent).

Another factor is removal percentage that is defined as follow:

$$
\% \text { Removal }=\frac{\left(c_{\mathrm{i}}-c_{\mathrm{l}}\right)}{\mathrm{c}_{\mathrm{i}}} \times 100
$$

Reaching equilibrium, when the adsorption and desorption rate on the absorbent was equal, and there isn't any significant change in heavy metal ions concentration of the solution; $\mathrm{q}_{\mathrm{e}}(\mathrm{mg} / \mathrm{g})$ and \% Removal are defined as the amount of adsorbed heavy metal onto the adsorbent per unit mass of adsorbent and removal percentage in the equilibrium state, respectively.

\subsubsection{Adsorption Isotherms}

Adsorption isotherms are offering quantitative relationships between the amount of the adsorbate on the surface of a solid material and concentration of that in the solution phase at a given temperature which investigation of them, is one of the most important ways to introduce a suitable adsorbent to heavy metals removal, in the adsorption process [22].

Langmuir, Freundlich and Tempkin isotherm models that are more use than other models are used in this study.

\subsubsection{Langmuir Isotherm}

This model based on the assumption that all adsorption active sites are equivalent and is homogeneous in terms of energy and has the same adsorption action [22]. In addition, adsorption is restricted to a monolayer and there are no lateral interactions between adsorbed molecules. The linearized related to this isotherm is represented by the following equation:

$$
\frac{c_{e}}{q_{g}}=\frac{1}{q_{\max } b}+\frac{c_{g}}{q_{\max }}
$$

$\mathrm{C}_{\mathrm{e}}$ is the concentration of remaining adsorbate in solution at equilibrium $(\mathrm{mg} / \mathrm{L}), \mathrm{q}_{\mathrm{e}}$ is the amount of adsorbate per gram of adsorbent at equilibrium $(\mathrm{mg} / \mathrm{g}), \mathrm{q}_{\max }(\mathrm{mg} / \mathrm{g})$ and $\mathrm{b}(\mathrm{L} / \mathrm{mg})$ are Langmuir constants related to the maximum adsorption capacity and adsorption energy, respectively.

In linear curve of $\frac{c_{\S}}{q_{g}}$ versus $C_{e}$, values of $\frac{1}{q_{\max }}$ and $\frac{1}{q_{\max } b}$ are slope and intercept, respectively; which the Langmuir constants is calculated using them. The essential characteristic of Langmuir equation is prediction whether an adsorption system is 'favorable' or 'unfavorable' could be expressed by dimensionless constant called equilibrium parameter $\mathrm{R}_{\mathrm{L}}$, which is defined from the following relation [25]: 
Bulletin de la Société Royale des Sciences de Liège, Vol. 85, 2016, p. 890 - 911

$$
\mathrm{R}_{\mathrm{L}}=\frac{1}{1+\mathrm{bc}_{\mathrm{o}}}
$$

$\mathrm{b}$ is Langmuir constant $(\mathrm{L} / \mathrm{mg})$, and $\mathrm{C}_{0}$ is the initial concentration of adsorbate in solution $(\mathrm{mg} / \mathrm{L})$.

As described by Hall et al. [31], $\mathrm{R}_{\mathrm{L}}$ values indicate the shape of isotherm: (1) unfavorable $\left(\mathrm{R}_{\mathrm{L}}>1\right)$, (2) linear $\left(\mathrm{R}_{\mathrm{L}}=1\right)$, (3) favorable $0<\mathrm{R}_{\mathrm{L}}<1$, and (4) irreversible $\left(\mathrm{R}_{\mathrm{L}}=0\right)$.

\subsubsection{Freundlich Isotherm}

This isotherm based on the assumption that the adsorbing surface is energetically heterogeneous and consisting of adsorption sites of various energies [22]. The linearized form of the Freundlich equation is as follows:

$$
\mathrm{Lnq}_{\mathrm{e}}=\mathrm{LnK}_{\mathrm{f}}+\frac{1}{\mathrm{n}} \mathrm{LnC}_{\mathrm{e}}
$$

$\mathrm{q}_{\mathrm{e}}$ is the amount of adsorbate per gram of adsorbent at equilibrium $(\mathrm{mg} / \mathrm{g}), \mathrm{C}_{\mathrm{e}}$ is the concentration of remaining adsorbate in solution at equilibrium $(\mathrm{mg} / \mathrm{L}), \mathrm{K}_{\mathrm{f}}$ and $\mathrm{n}$ are Freundlich constants related to the adsorption capacity $(\mathrm{mg} / \mathrm{g})$ and adsorption intensity $(\mathrm{g} / \mathrm{L})$, respectively.

In linear curve of $\mathrm{Lnq}_{\mathrm{e}}$ versus $\mathrm{LnC}_{\mathrm{e}}$, values of $\frac{1}{\mathrm{n}}$ and $\mathrm{LnK}_{\mathrm{f}}$ are slope and intercept, respectively; which the Freundlich constants is calculated using them. $\frac{1}{\mathrm{n}}$ is a dimensionless constant between zero and one, which $n=1$ represents the completely linear behavior between adsorption capacity and concentration of remaining adsorbate in solution at equilibrium. Whatever the value of $\mathrm{n}$ is more than 1 indicates that highly adsorption occurs in the high equilibrium concentration.

\subsubsection{Tempkin Isotherm}

Tempkin isotherm is given as [24]:

$$
\mathrm{q}_{\mathrm{e}}=\mathrm{BLn}\left(\mathrm{K}_{\mathrm{T}} \mathrm{C}_{\mathrm{e}}\right)
$$

It can be expressed in the linear form as:

$$
\mathrm{q}_{\mathrm{e}}=\mathrm{BLnK}_{\mathrm{T}}+\mathrm{BLnC}_{\mathrm{e}}
$$

$\mathrm{C}_{\mathrm{e}}$ is the concentration of remaining adsorbate in solution at equilibrium $(\mathrm{mg} / \mathrm{L}), \mathrm{q}_{\mathrm{e}}$ is the amount of adsorbate per gram of adsorbent at equilibrium $(\mathrm{mg} / \mathrm{g}), \mathrm{K}_{\mathrm{T}}$ is the equilibrium binding constant corresponding to the maximum binding energy $(\mathrm{mg} / \mathrm{L})$ and constant $B$ is related to the heat of adsorption $(\mathrm{L} / \mathrm{g})$. The isotherm constants are determined using curve of LnCe versus $\mathrm{q}_{\mathrm{e}}$, which $\mathrm{B}$ and $\mathrm{K}_{\mathrm{T}}$ are calculated using slope and intercept, respectively.

\section{RESULTS AND DISCUSSION}

\subsection{X-Ray Diffraction}

The crystalline nature of the $\gamma$-alumina prepared with aluminum isopropoxide in presence of tert-butanol alcoholic solvent was studied by X-ray diffraction. The resulting pattern in highangle diffraction is shown in figure 1. According to this figure and using the X'pert software, the three main reflections of $\gamma$-alumina phase are clearly observed as broad peaks at $2 \theta$ angles around $37^{\circ}, 46^{\circ}$, and $66^{\circ}$ which correspond to the [311], [400] and [440] planes respectively, are according with JCPDS PDF No. 001-1308 and indicate that transformations occurred from the boehmite phase to $\gamma$-alumina after calcination. The diffraction peaks observed in the XRD pattern were broad, because the crystallites were very small. Such a size indicates to their partly weak crystalline nature in the prepared $\gamma$-alumina. It should be noted that no peak of other phases 
of alumina is recognizable in the diffraction pattern of prepared sample and the $\gamma$-alumina phase is the only detectable phase.

The calculation was done for prepared $\gamma$-alumina based on Scherrer equation in the [440] planes with the most intensity of diffraction and $2 \theta$ angle value of $66^{\circ}$ that the average particle size (DXRD) was $5.4 \mathrm{~nm}$. The prepared sample had nanometer structure due to less than $100 \mathrm{~nm}$ size of the particles. Since the d-spacing could be considered a measure of the distance between layers in a crystal structure, the values calculated by the Bragg's law for the above peaks of the prepared sample XRD pattern are $0.239 \mathrm{~nm}, 0.198 \mathrm{~nm}$ and $0.141 \mathrm{~nm}$, respectively that indicates the decrease in this distance and thus reduction of the structure lattice parameter with increasing $\mathrm{X}$-ray diffraction angle.

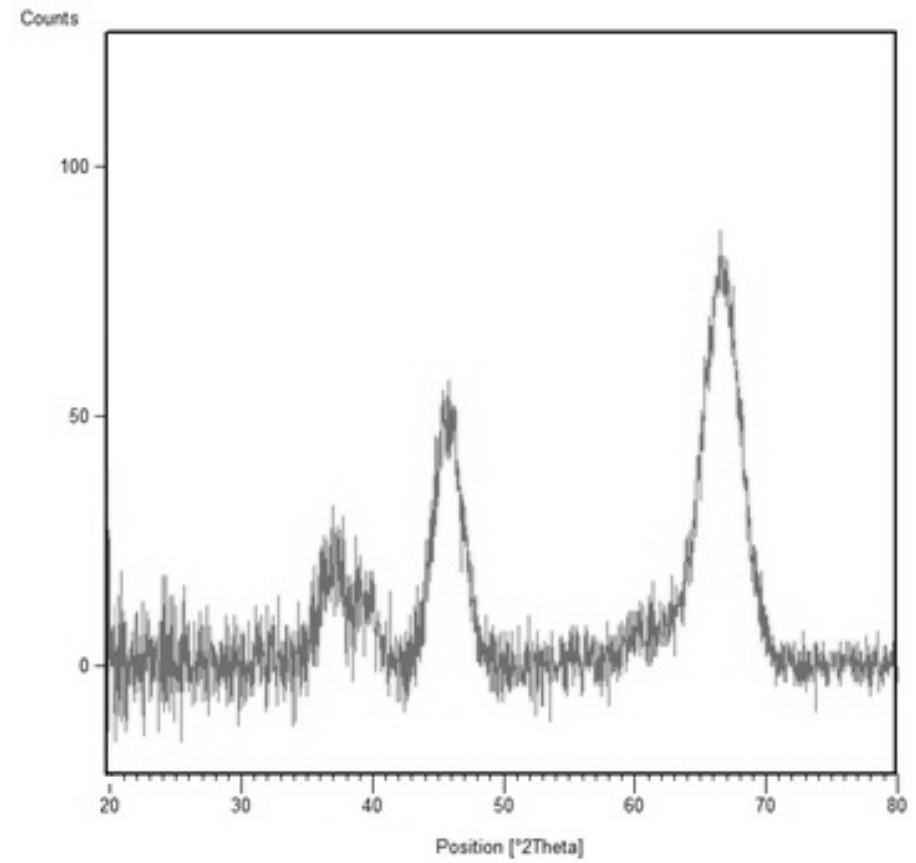

Fig. 1: X-ray diffraction pattern at high angles diffraction for prepared $\gamma$-alumina

\subsection{Textural Properties}

Textural properties of BET analysis consist of particles specific surface area, total pore volume and average pore diameter and also average particle size of the $\gamma$-alumina prepared via sol-gel method using aluminum isopropoxide in presence of tert-butanol solvent and acetic acid catalyst are presented in table 1 .

Table 1: Textural properties of prepared $\gamma$-alumina

\begin{tabular}{cccc}
\hline $\begin{array}{c}\text { Specific surface } \\
\text { area }\left(\mathrm{m}^{2} / \mathrm{g}\right)\end{array}$ & $\begin{array}{c}\text { Total pore } \\
\text { volume }\left(\mathrm{cm}^{3} / \mathrm{g}\right)\end{array}$ & $\begin{array}{c}\text { Average pore } \\
\text { diameter }(\mathrm{nm})\end{array}$ & $\begin{array}{c}\text { Average particle } \\
\text { size }(\mathrm{nm})\end{array}$ \\
\hline 351 & 1.09 & 12.43 & 5.34 \\
\hline
\end{tabular}


The nitrogen adsorption/desorption isotherm of the sol-gel derived $\gamma$-alumina is shown in figure 2. According to IUPAC classification, the obtained isotherm for this sample is characterized as $\mathrm{V}$ type. This isotherm has been extended in almost flat and stretched condition until reach high relative pressures, which is the characteristic of meso porosity solids. In addition, the significant mutation occurs in the curve at high relative pressures of about $\mathrm{P} / \mathrm{P}_{0}=$ 0.9 , which indicates presence of some macro pores in the structure of the sol-gel derived sample.

The shape of the hysteresis loops can be correlated with the change in pore structure, which in this case can be a phase transformation from boehmite to $\gamma$-alumina with different morphologies [28]. In this study, hysteresis loop for prepared sample occurred at a relative pressure range of $\mathrm{P} / \mathrm{P}_{0}=0.4-0.98$. It is $\mathrm{H} 1$ type that adsorption and desorption branches has parallel mode completely, so the most of pores are in cylindrical shape. The ultimate amount of adsorbed nitrogen by the sample is more than $600 \mathrm{~cm}^{3} / \mathrm{g}$, indicating presence of large volume pores.

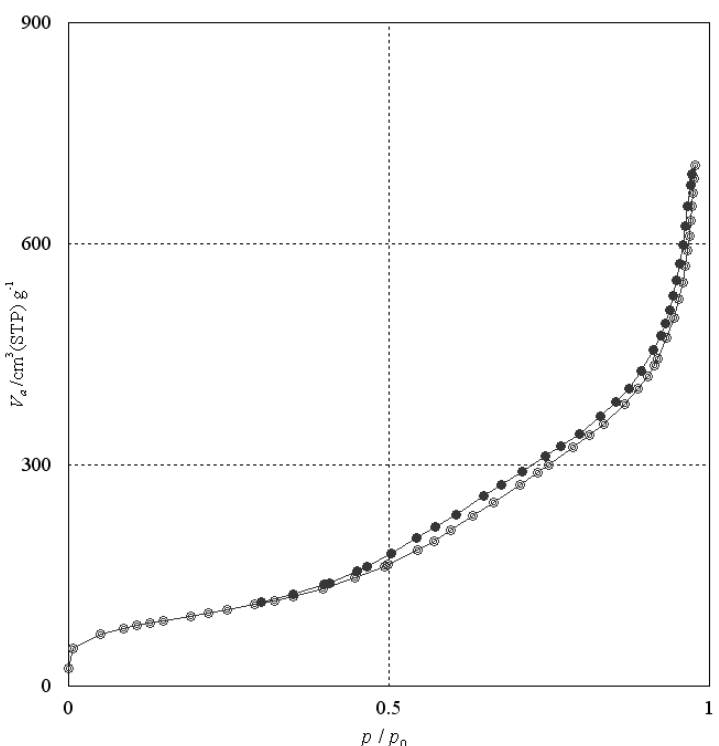

Fig. 2: Nitrogen adsorption/desorption isotherm for prepared $\gamma$-alumina

Pore size distribution of prepared $\gamma$-alumina obtained employing the $\mathrm{BJH}$ model is shown in figure 3. It indicates on relatively narrow uniform distribution of micro and mesopores with 1-10 nanometer sizes in the sample, which the related maximum peak is seen in $2.1 \mathrm{~nm}$. It is noteworthy, based on done research a narrow pore size distribution in the range of 1 to $10 \mathrm{~nm}$ of interest for both adsorption and catalytic applications [28]. 
Bulletin de la Société Royale des Sciences de Liège, Vol. 85, 2016, p. 890 - 911

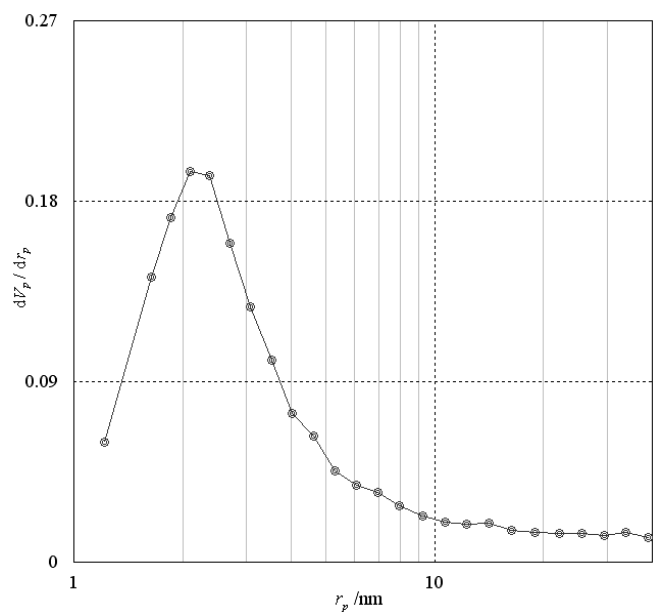

Fig. 3: BJH model of prepared $\gamma$-alumina

\subsection{Morphology}

Figure 4 shows the SEM image of the prepared $\gamma$-alumina sample which it has spongy structure and small particle sizes. These results are in good agreement with the crystallite sizes which are estimated by XRD and BET data. The SEM image shows a regular and porous morphology of prepared nanometer $\gamma$-alumina sample with different pore sizes and shapes.

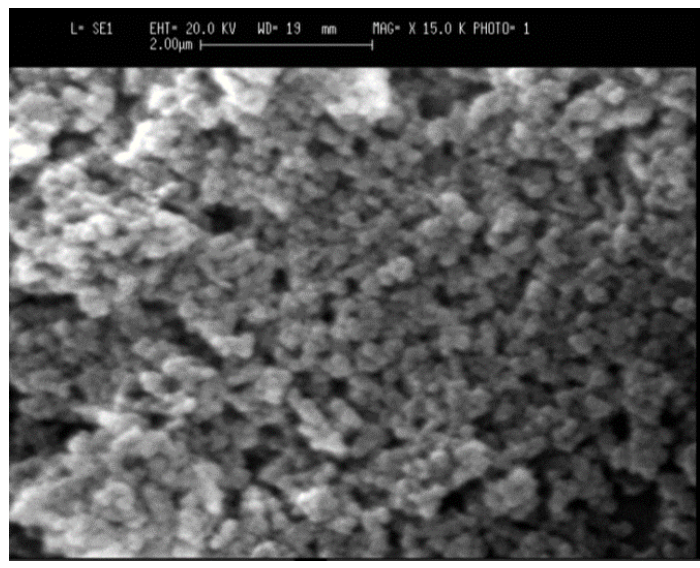

Fig. 4: SEM image of prepared $\gamma$-alumina $(\times 15000)$

\subsection{Proposed Mechanism for The $\gamma$-Alumina Nanoparticles Formation with High Specific Surface Area}

A sol-gel transfer reaction between precursor and solvent molecules may eventually affect the cross-linking mechanism in void regions of different sizes within the gel network.

In the present study, sol particles of boehmite form as a result of hydrolysis and condensation reactions. The slower hydrolysis and the faster condensation lead to formation of polymeric chains with high cross-linking and branching [32]. The enhanced cross-linking in the gel network resulted in larger voids regions which is agree with the observed higher specific surface area, the larger total pores volume, and the significant mesoporosity of the final products. On the other hand, discontinuity of the gel network may be referred to encapsulating of the sol particles of boehmite in the primary solution during drying process and solvent evaporation. 
In these conditions, the specific surface area of prepared $\gamma$-alumina depends on the extent of aggregation and dissolution of gel grains; so that aggregation of the gel grains lead to the formation of $\gamma$-alumina nanoparticles with higher specific surface area, and dissolution and decomposition of them bring formation of $\gamma$-alumina nanoparticles with lower specific surface area [33].

Intergrowth of the boehmite sol particles in the gel network occurred through hydrogen bonding and interspacing, in which alcohol as a solvent affected on the particle size and specific surface area, so that the specific surface area decreases with increasing of chain length of used alcohol, which could be caused by increasing pore sizes of the corresponding sample [34].

In acidic conditions, the encapsulated alkoxide particles decomposed upon calcination and resulting in further porosity, which may explain the formation of $\gamma$-alumina nanoparticles prepared from alkoxide. This mechanism supports the formation of mainly mesopores of smaller average diameter and the absence of noticeable amount of macropores in prepared $\gamma$-alumina nanoparticles, in presence of tert-butanol as a solvent. In this sample, pores were homogeneous and the final aggregates were ordered. This may be referred to the formation of small and homogeneous sol particles of the boehmite precursor.

Acetic acid plays some crucial role in controlling the microstructure of $\gamma$-alumina nanoparticles due to moderate boehmite particle growth speeds in different modes. That is probably through its selective adsorption on high-energy faces of boehmite particles during the aging process [35]. In these conditions, high energy levels would not be available for growth and therefore crystal growth speeds are significantly reduced because of the strong interaction between $\mathrm{CH}_{3} \mathrm{COO}$ groups of acetic acid and high energy levels of boehmite particles. On the other hand, due to gradually nucleation of boehmite during the aging process where no adsorption of acetic acid takes place; energy levels minimized and boehmite nanoparticles with specified morphology is formed.

\subsection{Adsorption studies: Lead removal by prepared $\gamma$-alumina nanoparticles 3.5.1. Effect of Contact Time}

The adsorption of $\mathrm{Pb}$ heavy metal on $\gamma$-alumina as a function of contact time was investigated at primary concentration of $200 \mathrm{mg} / \mathrm{L} \mathrm{of} \mathrm{Pb}, \mathrm{pH}$ value of $5.5 \pm 1$ and temperature of $293 \pm 2 \mathrm{~K}$ with adjusted shaking $300 \mathrm{rpm}$, during times of 3, 5, 10, 20, 30, 60 and 120 minutes. The heavy metal ions adsorption took place by the $\gamma$-alumina nanoparticles at the first 5 minutes of reaction as figure 5 shows which represents a high-speed adsorption process. All the places were empty in the early stages of the adsorption and rapid diffusion of Lead ions occurs from the aqueous solution to the outer surfaces of the $\gamma$-alumina nanoparticles. In the next step, low rate adsorption of these ions is due to long-distance diffusion of them into the internal pores of $\gamma$ alumina nanoparticles. 
Bulletin de la Société Royale des Sciences de Liège, Vol. 85, 2016, p. 890 - 911

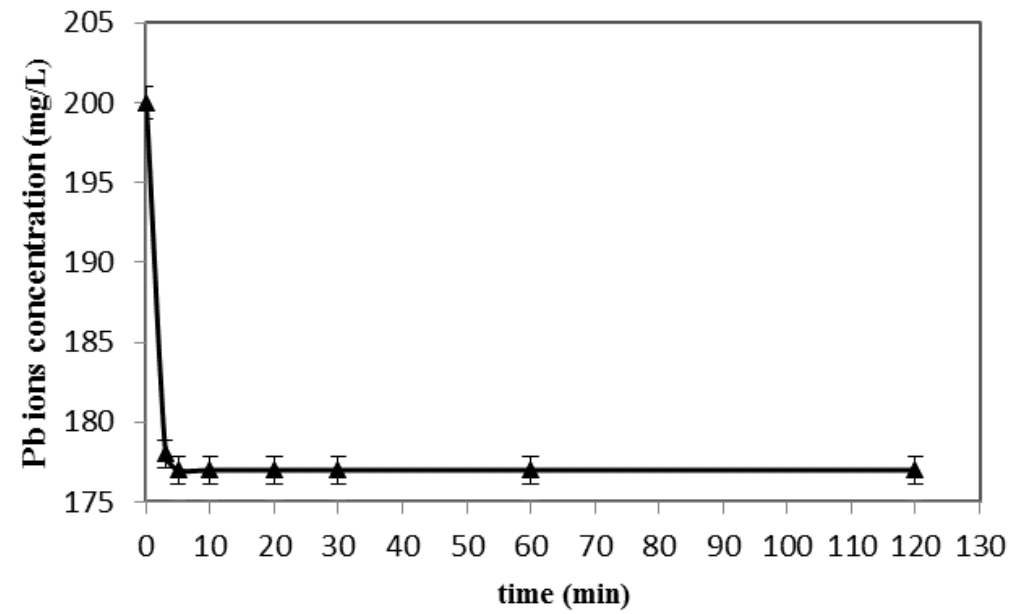

Fig. 5: Effect of contact time with $\gamma$-alumina nanoparticles on concentration decreasing of $\mathrm{Pb}^{2+}$ ions $(\mathrm{rpm}=300, \mathrm{pH}=5.5, \mathrm{~T}=293 \mathrm{~K})$

According to figure 6 can also be found that $\mathrm{Pb}^{2+}$ ion uptake is reached a maximum value, per unit mass of adsorbent material (adsorption capacity) after 5 minutes and equilibrium mode is obtained and then no significantly increase is seen with increasing contact time until 120 minutes.

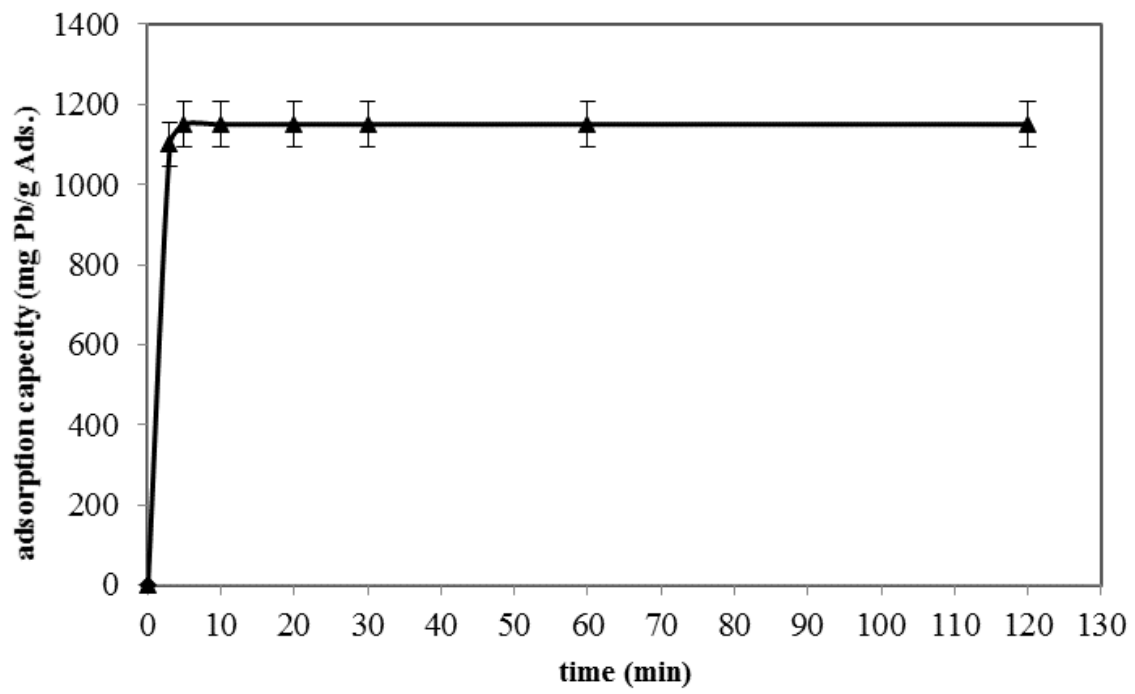

Fig. 6: Effect of contact time with $\gamma$-alumina nanoparticles on adsorption capacity of $\mathrm{Pb}^{2+}$ ions $(\mathrm{rpm}=300, \mathrm{pH}=5.5, \mathrm{~T}=293 \mathrm{~K})$

\subsubsection{Effect of Initial Concentration of Adsorbate}

Figure 7 shows adsorption capacity in initial concentrations of 100, 200, 300 and $400 \mathrm{mg} / \mathrm{L}$ of $\mathrm{Pb}^{2+}$ ions as a function of time. As seen up to a concentration of $400 \mathrm{mg} / \mathrm{L} \mathrm{of} \mathrm{Pb}^{2+}$ ions, adsorption is done from solution on the surface of the $\gamma$-alumina nanoparticles, completely. Also can be concluded that after 5 minutes of the process, variation in concentration is negligible and $\mathrm{Pb}$ adsorption process rate by $\gamma$-alumina nanoparticles has been equal with desorption speed. 
The results show that adsorption capacity in the solution increases with an increasing amount of initial concentration of heavy metal ions. Indeed, with a higher initial concentration, driving force is creating to overcome all the obstacles transfer heavy metal ions, between the solution and solid phase [36].

It is noteworthy that in the subsequent experiments the primary concentration of $200 \mathrm{mg} / \mathrm{L}$ of $\mathrm{Pb}$ was chosen as the initial concentration to investigate the effect of other factors on the uptake.

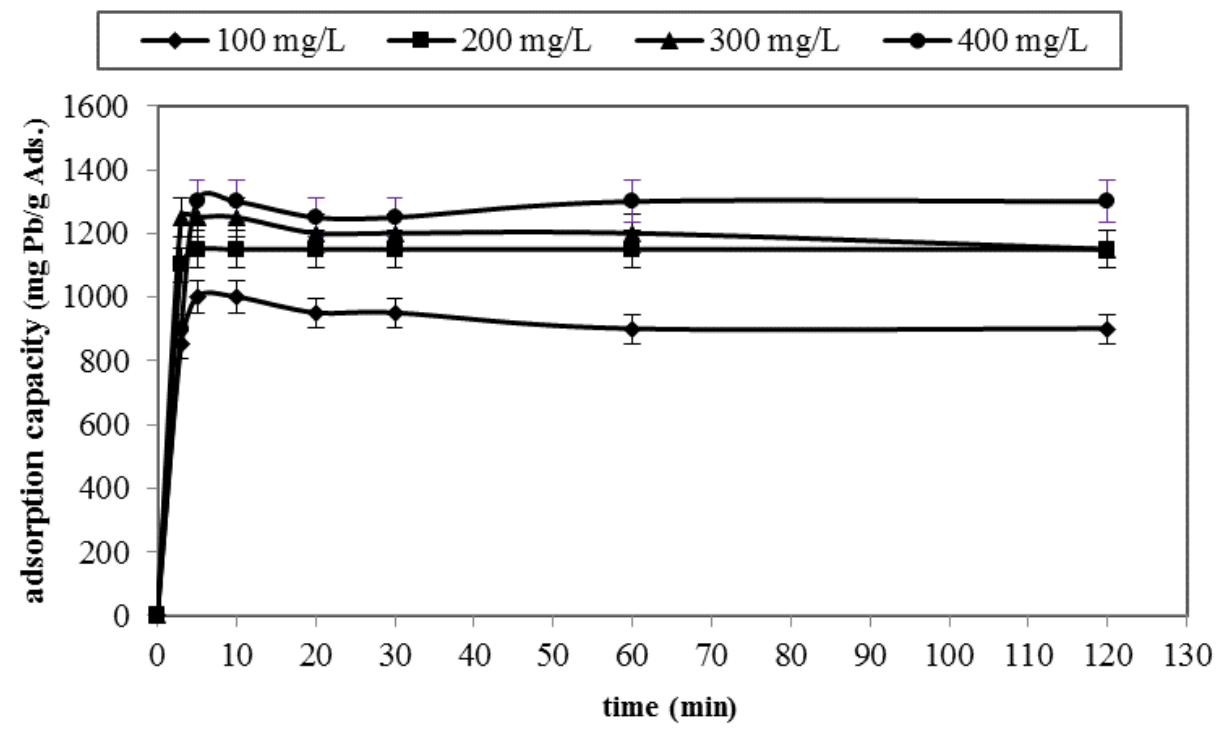

Fig. 7: Effect of contact time and initial concentration of $\mathrm{Pb}^{2+}$ ions on adsorption capacity $(\mathrm{rpm}=300, \mathrm{pH}=5.5, \mathrm{~T}=293 \mathrm{~K})$

\subsubsection{Effect of Adsorbent Mass}

The effect of different concentrations of adsorbent on $\mathrm{Pb}$ heavy metal adsorbtion onto the $\gamma$ alumina nanoparticles was investigated in different times. According to the figure 8 for 0.02 , 0.04 and $0.06 \mathrm{~g} / \mathrm{L}$ of $\gamma$-alumina nanoparticles adsorbent in balance conditions, adsorption capacity of $\mathrm{Pb}^{2+}$ ions are 1150,500 and $300 \mathrm{mg}$ of $\mathrm{Pb}$ per gram of adsorbent $\gamma$-alumina nanoparticles and removal percentage are 11.5, 10 and $9 \%$, respectively.

It was found that increasing the amount of adsorbent material reduced removal percentage of heavy metal ions; because more amount of adsorbent material caused reducing the contact area due to agglomeration of particles and overlap of active adsorption places.

As the figure shows the adsorption capacity is reduced with increase in the amount of adsorbent. Because it increased collisions between particles, thus particle aggregation and reduction of adsorbent specific surface area occurs. Also, increasing the amount of adsorbent, by increasing competition between the adsorbent particles, caused to reduction of adsorption capacity; that all of the above is justified by the 4 equation.

Above reviews indicate that the amount of adsorbent cannot be increase surface contact between metal ions and the adsorbent surface, infinitely. So to reduce the cost of doing adsorption process in various steps, suitable amount of adsorbent should be determined proportional to the initial concentration of adsorb and adsorption capacity, primarily. Accordingly, in this study, the $0.02 \mathrm{~g} / \mathrm{L}$ of $\gamma$-alumina nanoparticles adsorbent was used as the optimal value in each of the studies. 


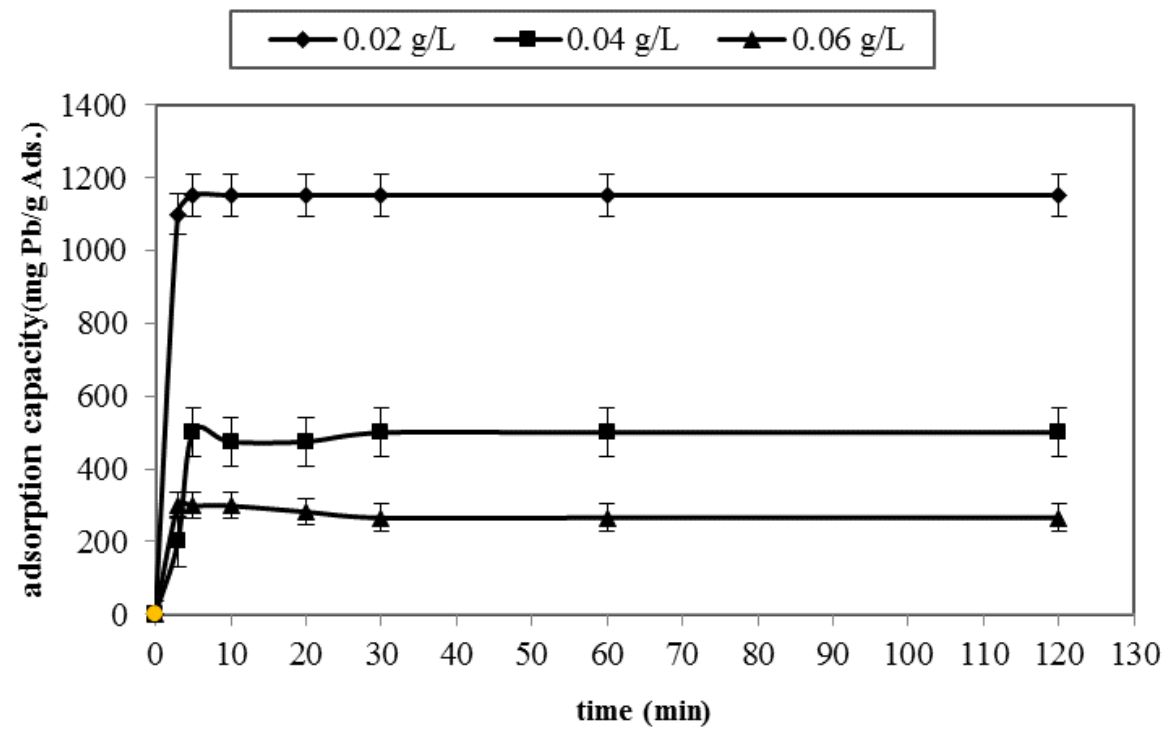

Fig. 8: Effect of contact time and adsorbent mass on adsorption capacity of $\mathrm{Pb}^{2+}$ ions $(\mathrm{rpm}=300, \mathrm{pH}=5.5, \mathrm{~T}=293 \mathrm{~K})$

\subsubsection{Effect of $\mathrm{pH}$ Values}

In this part, the role of $\mathrm{pH}$ has been investigated to heavy metals removal. For this purpose, by using a solution of nitric acid and ammonia, initial $\mathrm{pH}$ of the aqueous solution under constant conditions such as the amount of adsorption and adsorbent was set from 3 to 9 , in a range from acidic to alkaline environment. Adsorption capacity and removal percentage of $\mathrm{Pb}^{2+}$ ions in aqueous solution in 3 to $9 \mathrm{pH}$ is shown in figures 9 and 10, respectively. As seen after 5 minutes in different $\mathrm{pH}$, adsorption has stabilized nearly and adsorption process has reached to equilibrium.

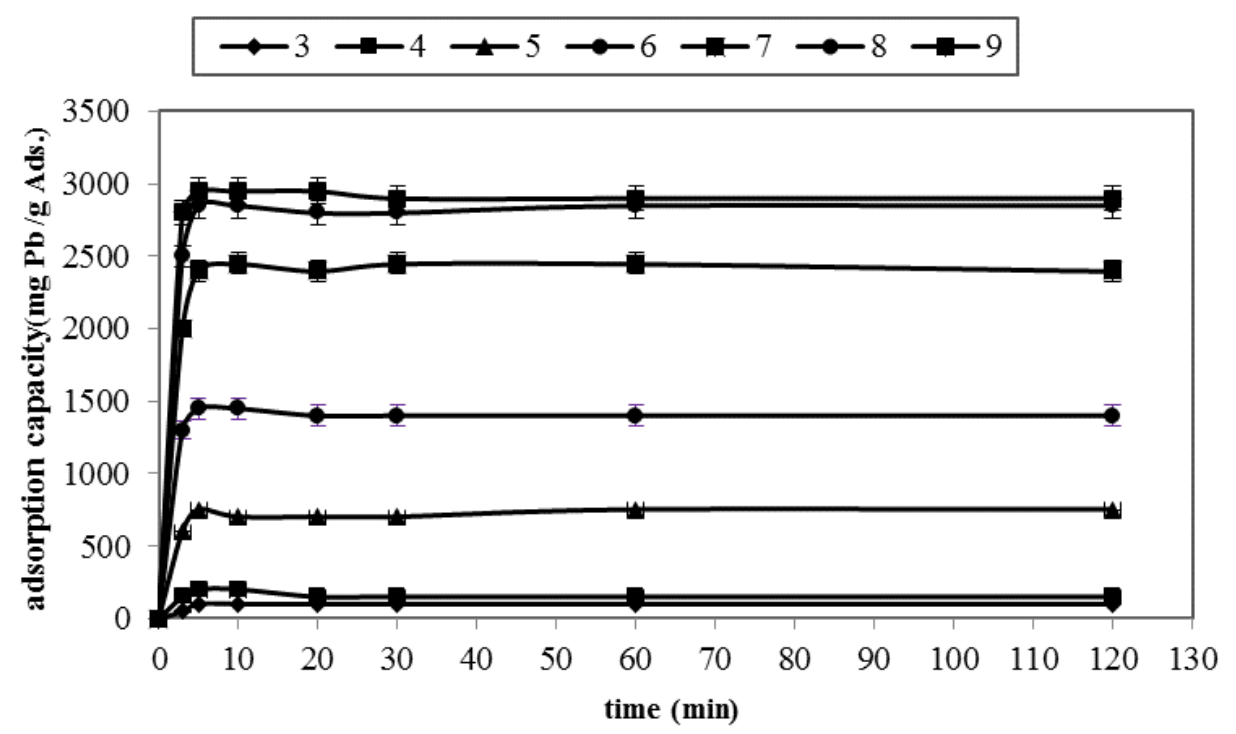

Fig. 9: Effect of contact time and aqueous solution $\mathrm{pH}$ on adsorption capacity of $\mathrm{Pb}^{2+}$ ions $\left(\mathrm{rpm}=300\right.$, adsorbent mass $=0.02 \mathrm{~g} / \mathrm{L}$, primary concentration of $\mathrm{Pb}^{2+}$ ion=200mg/L, T=293 K) 
At the basic $\mathrm{pH}$, the $\mathrm{OH}^{-}$on the surface of nano structured $\gamma$-alumina provides the binding cations ability. The decrease of $\mathrm{pH}$ leads to the neutralization of surface charge, and $\mathrm{OH}^{-}$is displaced from the surface. When the surface of $\gamma$-alumina nanoparticles carries negative charges, it facilitates to adsorb cations. The heavy metal removal percentage curve can be divided into three regions as figure 10 shows: (1) gradually increasing of the $\mathrm{Pb}$ adsorption from about $1 \%$ to $7.5 \%$ when the $\mathrm{pH}$ of the solution increases from 3 to 5 (region I); (2) in region II, the adsorption of $\mathrm{Pb}$ increases sharply on $\gamma$-alumina from $7.5 \%$ to $24 \%$ in the $\mathrm{pH}$ region of 5 to 7 ; and (3) from $\mathrm{pH} 7$ to $9, \mathrm{~Pb}$ is adsorbed gradually with a decreasing steep from $24 \%$ to $29.5 \%$ (region III).

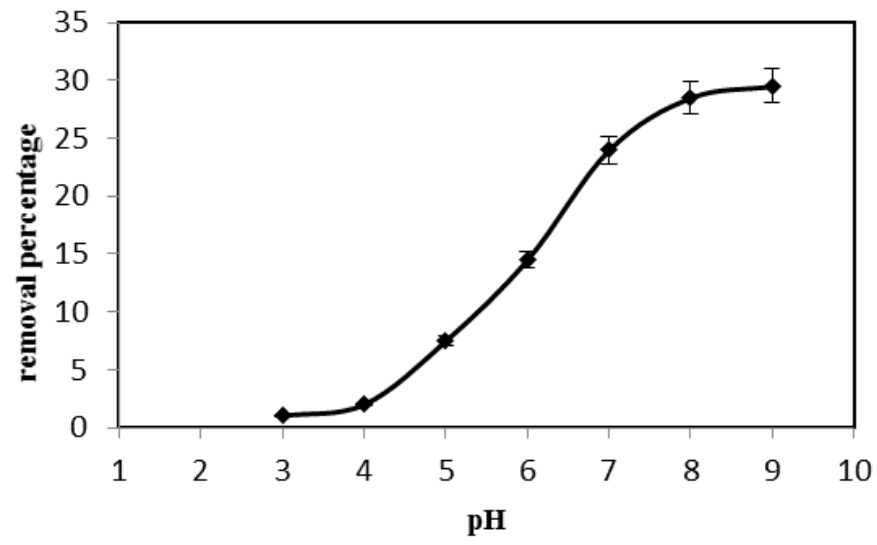

Fig. 10: The effect of aqueous solution $\mathrm{pH}$ on $\mathrm{Pb}^{2+}$ removal percentage $\left(\mathrm{rpm}=300\right.$, adsorbent mass $=0.02 \mathrm{~g} / \mathrm{L}$, primary concentration of $\mathrm{Pb}^{2+}$ ion=200mg/L, $\left.\mathrm{T}=293 \mathrm{~K}\right)$

Referred areas indicate on existence of different mechanisms for the adsorb process. Selective adsorption of $\mathrm{Pb}^{2+}$ ions by $\gamma$-alumina nanoparticles is due to the specific characteristics of $\mathrm{Pb}^{2+}$ ions that can be seen more in a specified $\mathrm{pH}$ range. Figure 11 shows the relationship between the relative amount of $\mathrm{Pb}^{2+}$ ions with $\mathrm{pH}$ in aqueous solution and the presence of $\mathrm{Pb}$ in the forms of $\mathrm{Pb}^{2+}, \mathrm{Pb}(\mathrm{OH})^{+}, \mathrm{Pb}(\mathrm{OH})_{2}, \mathrm{~Pb}(\mathrm{OH})_{3}{ }^{-}$, and $\mathrm{Pb}(\mathrm{OH})_{4}{ }^{2-}$ in different $\mathrm{pH}$ values [37].

According to this figure can be seen that $\mathrm{Pb}^{2+}$ ions are the main component of in aqueous solution up to approximately $\mathrm{pH}=7 . \mathrm{Pb}(\mathrm{OH})^{+}$positively charged factor is stable in the range of $\mathrm{pH}=5-11.5$ and at about $\mathrm{pH}=8.5$ reaches to a maximum. While bivalent $\mathrm{Pb}^{2+}$ hydroxide $\left(\mathrm{Pb}(\mathrm{OH})_{2}\right)$ began to deposit from $\mathrm{pH}=7.5$ and reached to a maximum in $\mathrm{pH}=10.5$, and is the main component of water solution. $\mathrm{Pb}(\mathrm{OH})_{4}{ }^{2-}$ and $\mathrm{Pb}(\mathrm{OH})_{3}{ }^{-}$negative factors are formed at above the 7.5 and $9 \mathrm{pH}$ respectively and are in the solution. So it can be concluded, in the area of I, in an acid environment and at 3 to $5 \mathrm{pH}$, since the adsorption mechanism is active only, there are competition between the $\mathrm{Pb}^{2+}$ and $\mathrm{H}^{+}$ions for being on the surface location and on the other hand because of $\mathrm{H}^{+}$ions surface of the adsorbent will be positively charged so the adsorption rate of $\mathrm{Pb}^{2+}$ ion is low. In area of II and by increasing the $\mathrm{pH}$ up to 7, despite the activation of $\mathrm{Pb}(\mathrm{OH})^{+}$ due to increasing of factors with negative charge in surface, the adsorption rate increases. In the area of III, the alkaline $\mathrm{pH}$ range and at 8 and $9 \mathrm{pH}$, a gradual increase in the adsorption of $\mathrm{Pb}$ on the surface of the $\gamma$-alumina nanoparticles can be attributed to the formation of different types of $\mathrm{Pb}$. Due to the presence dominant component of $\mathrm{Pb}(\mathrm{OH})^{+}$and a minor amount of $\mathrm{Pb}^{2+}, \mathrm{Pb}(\mathrm{OH})_{4}{ }^{2-}$ and $\mathrm{Pb}$ hydroxide factors in this area, also because of the negative charge on the surface of the 
adsorbent, both the mechanism of surface adsorption and precipitation of hydroxide phase acted in parallel that it tends to increase the adsorption amount. It should be noted that the contribution of adsorption mechanisms is higher compared to deposit formation mechanisms.

Accordingly, it can be found that the main $\mathrm{Pb}$ adsorb on the surface of the $\gamma$-alumina nanoparticles due to rapid and stable adsorption because of the appropriate places on the surface of the adsorbent and thus make a strong bond with adsorption places. This means that the main adsorption mechanism is not based on the deposition of $\mathrm{Pb}$ hydroxide species. Because according to the results at low $\mathrm{pH}$ a considerable adsorption takes place. Although decrease in the acidic $\mathrm{pH}$ can be due to competitive adsorption of $\mathrm{H}_{3} \mathrm{O}^{+}$ions which their concentration increase with $\mathrm{pH}$ decreasing. According to the results of previous studies in $\mathrm{pH}$ between 7.5 to $10, \mathrm{~Pb}$ adsorption along deposit of that on the surface of the adsorbent which this could be another reason for the significant increase of $\mathrm{Pb}$ adsorption in alkaline $\mathrm{pH}$ [38].

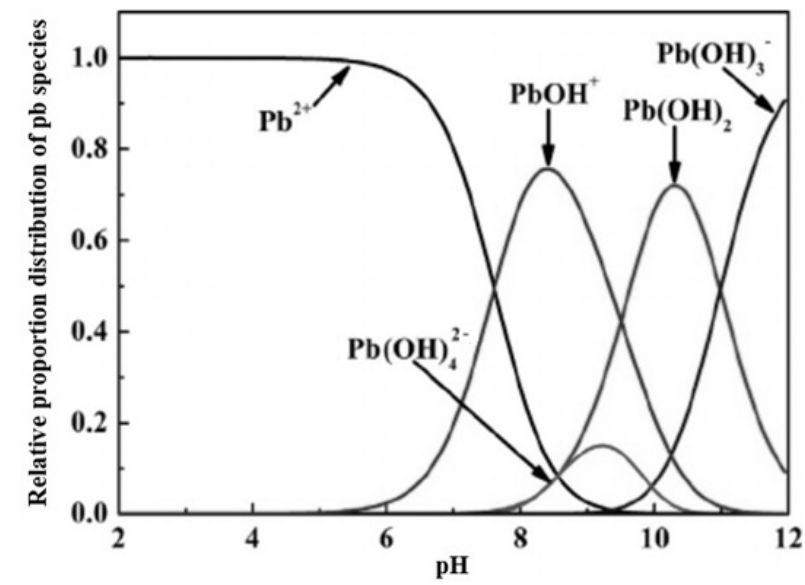

Fig. 11: Relative component distribution of variety of $\mathrm{Pb}$ as a function of $\mathrm{pH}$ in aqueous solution [37]

\subsubsection{Adsorption isotherms}

Linear graph of equivalent adsorption isotherms related to adsorption of $\mathrm{Pb}$ on the surface of $\gamma$-alumina nanoparticles is shown in figure 12, in the initial concentrations of 100, 200, 300 and $400 \mathrm{mg} / \mathrm{L}$ of $\mathrm{Pb}^{2+}$ ions at room temperature. Adsorption data were used for various isotherms, such as Langmuir, Freundlich and Tempkin isotherms. 
Bulletin de la Société Royale des Sciences de Liège, Vol. 85, 2016, p. 890 - 911
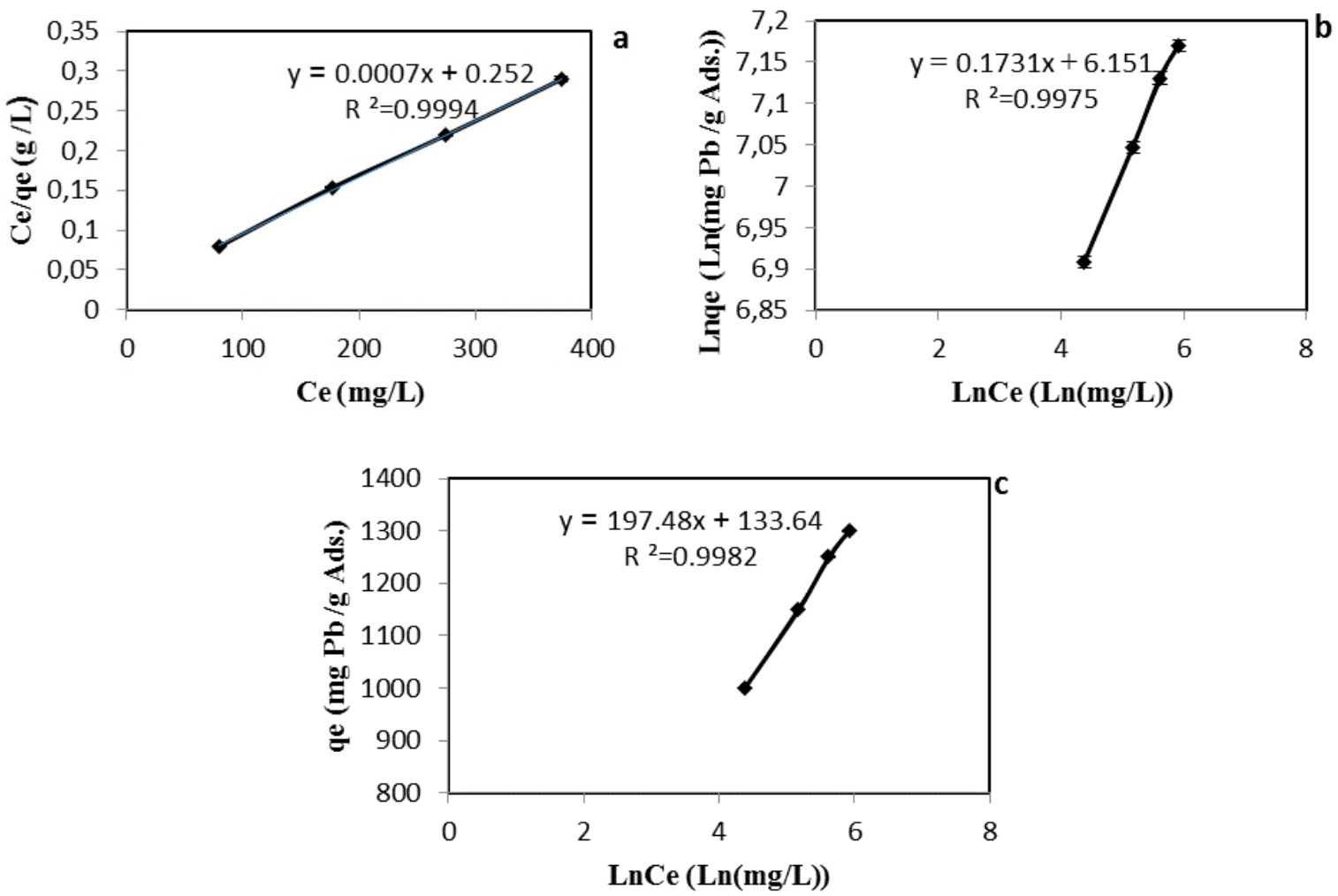

Fig. 12: Linear graph of equivalent adsorption isotherms

a) Langmuir b) Freundlich c) Tempkin for bivalent $\mathrm{Pb}^{2+}$ adsorb on the surface of $\gamma$-alumina nanoparticles (adsorbent mass=0.02 g/L, pH=5.5, T=293 K)

There is appropriate and well match between the theoretical models and data from experimental results according to the correlation coefficient of chart. Also, the resulting correlation coefficient characterized that the Langmuir adsorption isotherm, is the best isotherm, between existing models and is more compatible with the obtained results. Table 2 is presented obtained constants coefficient from isotherm equation.

Prediction of to be favorable adsorption system or not in Langmuir model is done by determination of $\mathrm{R}_{\mathrm{L}}$ dimensionless constants with the 7 equation. This value for bivalent $\mathrm{Pb}^{2+}$ adsorption, in the initial concentrations of $100,200,300$ and $400 \mathrm{mg} / \mathrm{L}$ of $\mathrm{Pb}^{2+}$ ions was obtained $0.26,0.15,0.11$ and 0.08 , respectively, on the surface of the $\gamma$-alumina nanoparticles that the values between 0 to 1 indicate having appropriate adsorption systems.

Table 2: Langmuir, Freundlich and Tempkin parameters for the adsorption of Lead on the surface of $\gamma$-alumina nanoparticles

\begin{tabular}{|c|c|c|c|c|c|c|c|c|}
\hline \multicolumn{3}{|c|}{ Langmuir parameters } & \multicolumn{3}{|c|}{ Freundlich parameters } & \multicolumn{3}{|c|}{ Tempkin parameters } \\
\hline $\begin{array}{c}\mathrm{q}_{\max } \\
(\mathrm{mg} / \mathrm{g})\end{array}$ & $\begin{array}{c}\mathrm{b} \\
(\mathrm{L} / \mathrm{mg})\end{array}$ & $\mathrm{R}^{2}$ & $\begin{array}{c}\mathrm{K}_{\mathrm{f}} \\
(\mathrm{mg} / \mathrm{g})\end{array}$ & $\begin{array}{c}\mathrm{n} \\
(\mathrm{g} / \mathrm{L})\end{array}$ & $\mathrm{R}^{2}$ & $\begin{array}{c}\mathrm{K}_{\mathrm{T}} \\
(\mathrm{mg} / \mathrm{L})\end{array}$ & $\begin{array}{c}\text { B } \\
(\mathrm{L} / \mathrm{g})\end{array}$ & $\mathrm{R}^{2}$ \\
\hline 1428.57 & 0.028 & 0.9994 & 469.19 & 5.78 & 0.9975 & 1.97 & 197.48 & 0.9982 \\
\hline
\end{tabular}




\subsection{Fourier Transform Infrared}

The adsorption capacity of an adsorbent is dependent on the chemical reactivity of functional groups at the adsorbent surface [39]. In this study, the created changes in the infrared spectrum bands was investigated after the adsorption of $\mathrm{Pb}^{2+}$ ions by the $\gamma$-alumina powder.

The presence of $\mathrm{Pb}^{2+}$ ions (not detected by X-ray diffraction, due to its low content) has been confirmed by infrared spectroscopy. Fig. 13 shows the Fourier Transform Infrared (FTIR) spectra for the $\gamma$-alumina powder recorded in $\mathrm{KBr}$ pellet before and after $\mathrm{Pb}^{2+}$ adsorption. There were significant changes on FTIR spectrum of $\gamma$-alumina after interaction with $\mathrm{Pb}^{2+}$ ions.

The strong broadening band at $3800-3000 \mathrm{~cm}^{-1}$ occurs due to the hydrogen bond between the various hydroxyl groups in the $\gamma$-alumina powder.

Another broadening band at $1000-400 \mathrm{~cm}^{-1}$ correspond to $\mathrm{Al}-\mathrm{O}$ vibration existed. The broad $-\mathrm{OH}$ stretching adsorption band appeared at $3473.02 \mathrm{~cm}^{-1}$ reveals the presence of hydroxyl groups. The adsorption band appeared at $798.84 \mathrm{~cm}^{-1}$ represents aluminum ions. These results are in agreement with the FTIR spectrum of $\gamma$-alumina as reported elsewhere [40 and 41].

Comparing the FTIR spectra of $\gamma$-alumina powder before and after $\mathrm{Pb}^{2+}$ adsorption (a and $\mathrm{b}$ ) shows decreasing of the $-\mathrm{OH}$ stretching mode intensity, appearing the bending mode of $\mathrm{Pb}^{2+}$ at $586.98 \mathrm{~cm}^{-1}$ and new peaks at 2927.81 and $1384.53 \mathrm{~cm}^{-1}$ and disappearing of the three peaks at $2104.05,1084.05$ and $798.84 \mathrm{~cm}^{-1}$ after adsorption process. It is indicating that these groups participate in the adsorption process. Also, adsorption band related to $\mathrm{OH}^{-}$groups shifted from $3473.02 \mathrm{~cm}^{-1}$ to $3492.85 \mathrm{~cm}^{-1}$ following $\mathrm{Pb}^{2+}$ adsorption.

An obvious change in the peak position and intensity at $900-500 \mathrm{~cm}^{-1}$ region in spectra of $\gamma$ alumina powder after $\mathrm{Pb}^{2+}$ adsorption could be assigned to the formation of $\mathrm{Pb}-\mathrm{O}$ and also $\mathrm{O}-$ $\mathrm{Pb}-\mathrm{O}$ bond. In $\gamma$-alumina powder after $\mathrm{Pb}^{2+}$ adsorption distinct peak at $586.98 \mathrm{~cm}^{-1}$ and changes in peak position and intensity around $1100-500 \mathrm{~cm}^{-1}$ can be assigned to asymmetric stretching vibration of $\mathrm{Pb}-\mathrm{O}$ and stretching vibration of weakly bonded $\mathrm{O}^{2-}$ atom with $\mathrm{Pb}^{2+}$. 


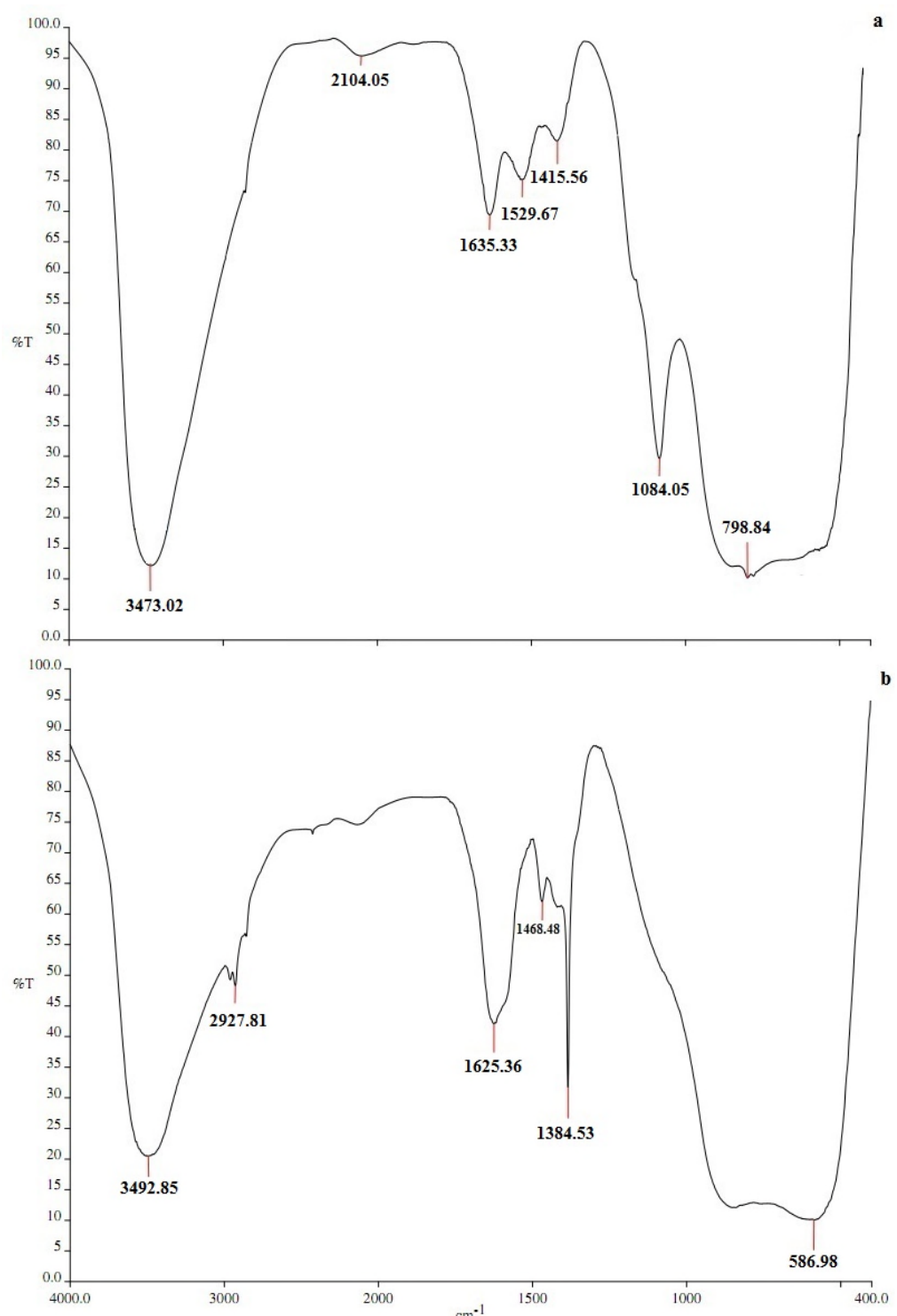

Fig. 13: FTIR spectra of $\gamma$-alumina powder a) before and b) after $\mathrm{Pb}^{2+}$ adsorption

\section{CONCLUSION}

The present study was successful in synthesizing porous $\gamma$-alumina nanoparticles using a facile sol-gel process. The prepared $\gamma$-alumina in the presence of tert-butanol as a solvent even after calcining process of the boehmite at $600^{\circ} \mathrm{C}$ had a specific surface area of $351 \mathrm{~m}^{2} / \mathrm{g}$, a pore volume of $1.09 \mathrm{~cm}^{3} / \mathrm{g}$, particle size of $5.34 \mathrm{~nm}$ and suitable pore size distribution which are desirable for heavy metal adsorption. This work also showed that prepared $\gamma$-alumina powder had the great adsorption performance of $\mathrm{Pb}^{2+}$ with a high adsorption rate and adsorption capacity of $1150 \mathrm{mg} / \mathrm{g}$ when the adsorption reached equilibrium for $5 \mathrm{~min}$ at room temperature and $\mathrm{pH}=5.5$.

\section{ACKNOWLEDGEMENTS}

The authors gratefully acknowledge from the Material and Energy Research Center (MERC) and the Iranian Nanotechnology Initiative Council for their financial supports of this study. 
Bulletin de la Société Royale des Sciences de Liège, Vol. 85, 2016, p. 890 - 911

\section{REFRENCES}

[1] César Lúcio Lopes de Faria, Tânia Keli Resende de Oliveira, Vera Lúcia dos Santos, Carlos Augusto Rosa, José Domingos Ardisson, Waldemar de Almeida Macêdo, Armindo Santos, "Usage of the sol-gel process on the fabrication of macroporous adsorbent activated-gamma alumina spheres", Journal of Microporous and Mesoporous Materials, 120 (2009) 228-238.

[2] Y.W. Jun, J.S. Choi, J.W. Cheon, "Shape Control of Semiconductor and Metal Oxide Nanocrystals through Nonhydrolytic Colloidal Routes, A review", Journal of Angewandte Chemie International Edition in English, 45 (2006) 3414-3439.

[3] G.F. Zou, H. Li, Y.G. Zhang, K. Xiong, Y.T. Qian, "Solvothermal/hydrothermal route to semiconductor nanowires", Journal of Nanotechnology, 17 (2006) S313.

[4] J. Wang, Y. Wang, M. Qiao, S. Xie, K. Fan, "A novel sol-gel synthetic route to alumina nanofibers via aluminum nitrate and hexamethylenetetramine", Journal of Materials Letters, 61 (2007) 5074-5077.

[5] M. Rajendran, A.K. Bhattacharya, "A process for the production of sub-micron to millimetre sized thermally stable $\alpha$-alumina spheres", Journal of Materials Science and Engineering: B, 60 (1999) 217-222.

[6] M. Vallet-Regí, L. Rodríguez-Lorenzo, C.V. Ragel, A.J. Salinas, J.M. González-Calbet, "Control of structural type and particle size in alumina synthesized by the spray pyrolysis method", Journal of Solid State Ionics, Part 1 (1997) 197-203.

[7] Z. Károly, J. Szépvölgyi, "Hollow alumina microspheres prepared by RF thermal plasma", Journal of Powder Technology, 132 (2003) 211-215.

[8] M.G. Ma, Y.J. Zhu, Z.L. Xu, "A new route to synthesis of $\gamma$-Alumina nanorods", Journal of Materials Letters, 61 (2007) 1812-1815.

[9] H.Y. Zhu, J.D. Riches, J.C. Barry, " $\gamma$-Alumina Nanofibers Prepared from Aluminum Hydrate with Poly (ethylene oxide) Surfactant", Journal of Chemistry of Materials, 14 (2002) 2086-2093.

[10] S. Shen, Q. Chen, P. Chow, G. Tan, X. Zeng, Z. Wang, R. Tan, "Steam-Assisted Solid WetGel Synthesis of High-Quality Nanorods of Boehmite and Alumina", Journal of Physical Chemistry: C, 111 (2007) 700-707.

[11] V.R. Palkar, "Sol-gel derived nanostructured $\gamma$-Alumina porous spheres as an adsorbent in liquid chromatography", Journal of Nano Structured Materials, 11(1999) 369-374.

[12] L. Ji, J. Lin, K.L. Tan, H.C. Zeng, "Synthesis of High-Surface-Area Alumina Using Aluminum Tri-sec-butoxide - 2, 4-Pentanedione - 2-Propanol - Nitric Acid Precursors", Journal of Chemistry of Materials, 12 (2000) 931-939.

[13] J. Sanchez-Valente, X. Bokhimi, J.A. Toledo, "Synthesis and catalytic properties of nanostructured aluminas obtained by sol-gel method", Journal of Applied Catalysis A: General, 264 (2004) 175-181.

[14] Seung-Moon Kim, Yun-Jo Lee, Jong Wook Bae, H.S. Potdar, Ki-Won Jun, "Synthesis and characterization of a highly active alumina catalyst for methanol dehydration to dimethyl ether", Journal of Applied Catalysis A: General, 348 (2008) 113-120.

[15] Baiyu Huang, Calvin H. Bartholomew, Brian F. Woodfield, "Facile synthesis of mesoporous $\gamma$-Alumina with tunable pore size: The effects of water to aluminum molar ratio in hydrolysis of aluminum alkoxides", Journal of Microporous and Mesoporous Materials, 183 (2014) 37-47.

[16] Ahmad Reza Keshavarz, Mehran Rezaei, Fereydoon Yaripour, "Preparation of nanocrystalline $\gamma-\mathrm{Al}_{2} \mathrm{O}_{3}$ catalyst using different procedures for methanol dehydration to dimethyl ether", Journal of Natural Gas Chemistry, 20 (2011) 334-338. 
Bulletin de la Société Royale des Sciences de Liège, Vol. 85, 2016, p. 890 - 911

[17] Guangci Li, Yunqi Liu, Chenguang Liu, "Solvothermal synthesis of gamma aluminas and their structural evolution", Journal of Microporous and Mesoporous Materials, 167 (2013) 137 145.

[18] Xun Liu, Tianyou Peng, Jinchun Yao, Hongjin Lv, Cheng Huang, "Synthesis and textural evolution of alumina particles with mesoporous structures", Journal of Solid State Chemistry, 183 (2010) 1448-1456.

[19] H.S. Potdar, Ki-Won Jun, Jong Wook Bae, Seung-Moon Kim, Yun-Jo Lee, "Synthesis of nano-sized porous $\gamma$-alumina powder via a precipitation/digestion route", Journal of Applied Catalysis A: General, 321 (2007) 109-116.

[20] S. Wang, X. Li, S. Wang, Y. Li, Y. Zhai, "Synthesis of $\gamma$-alumina via precipitation in ethanol", Journal of Materials Letters, 62 (2008) 3552-3554.

[21] M.E. Mahmoud, M.M. Osman, O.F. Hafez, A.H. Hegazi, E. Elmelegy, "Removal and preconcentration of lead(II) and other heavy metals from water by alumina adsorbents developed by surface-adsobed-dithizone", Journal of Desalination, 251 (2010) 123-130.

[22] Yvan J.O. Asencios, María R. Sun-Kou, "Synthesis of high-surface-area $\gamma-\mathrm{Al}_{2} \mathrm{O}_{3}$ from aluminum scrap and its use for the adsorption of metals: $\mathrm{Pb}(\mathrm{II}), \mathrm{Cd}(\mathrm{II})$ and $\mathrm{Zn}(\mathrm{II})$ ", Journal of Applied Surface Science, 258 (2012) 10002-10011.

[23] A. K. Patra, A. Dutta, A. Bhaumik, "Self-assembled mesoporous $\gamma-\mathrm{Al}_{2} \mathrm{O}_{3}$ spherical nanoparticles and their efficiency for the removal of arsenic from water", Journal of Hazardous Materials, 201-202 (2012) 170-177.

[24] A. Rahmani, H. Zavvar Mousavi, M. Fazli, "Effect of nanostructure alumina on adsorption of heavy metals", Journal of Desalination, 253 (2010) 94-100.

[25] H. Zhang, L. Chen, D. Zhang, S. Lu, X. Yu, "Impact of environmental conditions on the adsorption behavior of radionuclide ${ }^{63} \mathrm{Ni}$ (II) on $\gamma-\mathrm{Al}_{2} \mathrm{O}_{3}$ ", Journal of Colloids and Surfaces A: Physicochemical and Engineering Aspects, 380 (2011) 16-24.

[26] M. Burgos, M. Langlet, "The sol-gel transformation of TIPT coatings: a FTIR study", Journal of Thin Solid Films, 349 (1999) 19-23.

[27] B.D. Cullity, S.R. Stock, "Elements of X-Ray Diffraction", U.S.A, Prentice Hall, 2001.

[28] S. Lowell, J. E. Shields, "Powder Surface Area and Porosity", Chapman and Hall, London and New York, 1984.

[29] Zahra Hosseini, Majid Taghizadeh, Fereydoon Yaripour, "Synthesis of nanocrystalline $\gamma-$ $\mathrm{Al}_{2} \mathrm{O}_{3}$ by sol-gel and precipitation methods for methanol dehydration to dimethyl ether", Journal of Natural Gas Chemistry, 20 (2011) 128-134.

[30] A.K. Bhattacharya, S.N. Mandal, S.K. Das, "Adsorption of Zn(II) from aqueous solution by using different adsorbents", Journal of Chemical Engineering, 123 (2006) 43-51.

[31]. Hall, K.R., Eagleton, L.C., Acrivos, A. and Vermeulen, T. Poreand, "Solid-Diffusion Kinetics in Fixed-Bed Adsorption under Constant-Pattern Conditions", Journal of Industrial and Engineering Chemistry Fundamentals, 5 (1966) 212-223.

[32] C. Brinker, G. Scherer, "Sol-Gel Science", Academic Press, 1989.

[33] K. Hellgardt, D. Chadwick, "On the preparation of high surface area aluminas from nitrate solutions", Journal of Industrial and Engineering Chemistry Research, 37 (1998) 405-411.

[34] S.J. Gregg, K.S.W. Sing, "Adsorption, surface area and porosity", Academic Press, 1982.

[35] S.B. Deshpande, H.S. Potdar, Y.B. Khollam, K.R. Patil, R. Pasricha, N.E. Jacob,"Room temperature synthesis of mesoporous aggregates of anatase $\mathrm{TiO}_{2}$ nanoparticles", Journal of Materials Chemistry and Physics, 97 (2006) 207-212. 
[36] Z. Aksu, S. Tezar, "Biosorption of reactive dyes on the green alga Chlorella vulgaris", Journal of Process Biochemistry, 40 (2005) 1347-1361.

[37] S. Duan, R. Tang, Z. Xue, X. Zhang, Y. Zhao, W. Zhang, J. Zhang, B. Wang, S. Zeng, D. Sun, "Effective removal of $\mathrm{Pb}$ (II) using magnetic $\mathrm{Co}_{0.6} \mathrm{Fe}_{2.4} \mathrm{O}_{4}$ micro-particles as the adsorbent: Synthesis and study on the kinetic and thermodynamic behaviors for its adsorption", journal of Colloids and Surfaces A: Physicochemical and Engineering Aspects, 469 (2015) 211-223.

[38] T. C. Tan, W. K. Teo, "Combined effect of carbon dosage and initial adsorbate concentration on the adsorption isotherm of heavy metals on activated carbon", Journal of Water Research, 21 (1987) 1183-1188.

[39] Dayane J. Amorim, Hélen C. Rezende, Érica L. Oliveira, Ione L. S. Almeida, Nívia M. M. Coelho, Túlio N. Matos, Cleide S. T. Araújo, "Characterization of Pequi (Caryocar brasiliense) Shells and Evaluation of Their Potential for the Adsorption of Pb(II) Ions in Aqueous Systems", Journal of the Brazilian Chemical Society , 27 (2016) 616-623.

[40] Z. Zeng, J. Yu, Z.X. Guo, "Preparation of functionalized core-shell alumina/polystyrene composite nanoparticles", Journal of Macromolecular Chemistry and Physics, 206 (2005) 15581567.

[41] G. Busca, V. Lorenzelli, G. Ramis, R.J. Willey, "Surface sites on spinel-type and corundumtype metal oxide powders", Journal of Langmuir, 9(1993) 1492-1499. 